\title{
TURISMO GASTRONÔMICO: UMA PESQUISA BIBLIOMÉTRICA EM BASES DE DADOS NACIONAIS E INTERNACIONAIS
}

\author{
GASTRONOMIC TOURISM: A BIBLIOMETRIC SURVEY OF NATIONAL AND \\ INTERNATIONAL DATABASES
}

\section{TURISMO GASTRONÓMICO: UNA INVESTIGACIÓN BIBLIOMÉTRICA EN BASES DE DATOS NACIONALES E INTERNACIONALES}

Clarissa de Souza Ribeiro-Martins Doutoranda em Saúde e Comportamento (Universidade Católica de Pelotas - UCPel) Mestra em Saúde e Comportamento (Universidade Católica de Pelotas - UCPel) ntcissa@gmail.com

Elvis Silveira-Martins Professor Permanente do Programa de Pós-Graduação em Desenvolvimento Territorial e Sistemas Agroindustriais (PPGDTSA) e Mestrado Profissional em Administração Pública (PROFIAP) da Universidade Federal de Pelotas - UFPel Doutor em Administração e Turismo (Universidade do Vale do Itajaí - UNIVALI) elvis.professor@gmail.com

Data de Submissão: 07/06/2017 Data de Aceitação: 01/09/2017

RESUMO: Esta pesquisa objetiva realizar um levantamento bibliométrico sobre o construto turismo gastronômico em bases de dados nacionais e internacionais. Foram analisados 45 artigos identificados nas bases de dados periódicos CAPES, Spell, Proquest, Ebsco. Realizaram-se diferentes análises como: evolução temporal, identificação dos periódicos, cálculo da lei de Bradford, tipos de pesquisas realizadas, centralidade de Freeman, redes de autores, mensuração do poder de Bonacich, comparativo com a Lei de Lotka, redes de universidades, trabalhos com maior número de referências, principais palavras dos objetivos. Verificou-se, entre outros aspectos, que o core do assunto são os periódicos: Casos, Rosa dos Ventos, além das revistas Estudios y Perspectivas en Turismo, Tourism \& Management e TuryDes. Ainda, o autor mais referenciado é Michael Hall, no entanto o trabalho com maior número de referências é de Erik Cohen. $O$ pesquisador Emilio Morales-Fernández e as universidades de Aveiro e Loyola Andalucía realizam o maior número de parcerias científicas.

PALAVRAS-CHAVE: turismo gastronômico; turismo; gastronomia; bibliométrica.

ABSTRACT: The aim of this study is to conduct a bibliometric survey on the construct of gastronomic tourism in the national and international periodical databases. Forty-five articles were identified in the Capes, Spell, Proquest and Ebsco databases, and analyzed. Different analyses were carried out, such as temporal evolution, identification of journals, calculation of the Bradford law, types of research carried out, Freeman's centrality, author's networks, Bonacich's power measurement, comparative with Lotka's law; networks of universities, works with the highest number of references, and main words mentioned in the objectives. It was verified, among other aspects, that the core of the subject is the periodicals: Casos and Rosa dos Ventos, as well as the journals Estudios y Perspectivas en Turismo, Tourism \& Managemen, and TuryDes. The most referenced author is Michael Hall, but the work with most references is Erik Cohen. The researcher Emilio Morales-Fernández and the universities of Aveiro and Loyola Andalucía have the highest number of scientific partnerships.

KEYWORDS: gastronomic tourism; tourism; gastronomy; bibliometric. 
Resumen: Esta investigación tiene como objetivo realizar un levantamiento bibliométrico sobre el constructo turismo gastronómico en bases de datos nacionales e internacionales. Se analizaron 45 artículos identificados en las bases de datos periódicos Capes, Spell, Proquest, Ebsco. Se realizaron diferentes análisis tales como evolución temporal, identificación de los periódicos, cálculo de la ley de Bradford, tipos de investigaciones realizadas, centralidad de Freeman, redes de autores, medición del poder de Bonacich, comparativo con la ley de Lotka, redes de universidades, trabajos con mayor número de referencias, principales palabras de los objetivos. Se verificó, entre otros aspectos, que el núcleo del asunto son los periódicos Casos, Rosa de los Vientos, además de las revistas Estudios y Perspectivas en Turismo, Turismo \& Management y TuryDes. El autor más referenciado es Michael Hall, sin embargo el trabajo con mayor número de referencias es el de Erik Cohen. El investigador Emilio Morales-Fernández y las universidades de Aveiro y Loyola, Andalucía, realizan el mayor número de alianzas científicas.

PALABRAS CLAVE: Turismo gastronómico; Turismo; Gastronomía; Bibliométrica.

\section{INTRODUÇÃO}

ientistas e demais profissionais interessados na área de turismo
frequentemente dedicam suas agendas de pesquisas para
entender as múltiplas faces desta área envolta em dinamismo, influências sociais, emocionais e ambientais, a qual impacta diretamente, conforme Silveira-Martins \& Zonatto (2015) e Silveira-Martins et al. (2016), o ambiente em que está atrelada, bem como as organizações que se valem deste posicionamento. Neste contexto, verifica-se que uma das vertentes que desperta interesse de estudo está intrinsecamente associada com a alimentação - o turismo gastronômico.

A partir do momento que a alimentação começou a ganhar uma conotação diferente à do simples ato de satisfazer uma necessidade humana e passou a ofertar prazeres, memórias, sensações alinhadas a um contexto social, cultural e histórico de determinados povos e/ou região, motivou a área de turismo a estudar e compreender suas particularidades. Assim, o turismo gastronômico pode ser identificado como uma poderosa ferramenta de desenvolvimento regional, empregabilidade, manutenção das culturas e hábitos de determinado povo, além do que o escopo de atuação transcende o local findo de alimentação envolvendo toda a rota até ali.

Desta maneira, o turismo gastronômico é conceituado por Londoño (2015) como a atividade em que boa comida e bebida podem ser apreciadas durante as férias. Em complemento, Forné (2016) afirma que este tipo de turismo não tem a motivação principal no deslocamento do turista e, por esta característica, 
pode estar presente em qualquer viagem. Todavia, Gordin, Trabskaya e Zelenskaya (2016) ressaltam que o mercado turístico moderno está mudando em uma tentativa de atender a novas tendências de modelos de consumo. Assim, cientistas da área compreendem que a gastronomia é um componente flexível de uma oferta turística capaz de se ajustar a essas tendências.

Tendo em vista a relevância e o caráter contributivo do turismo gastronômico, tanto para a sociedade como para a economia local/regional, parece ser oportuno pesquisar o que já foi publicado e, desta maneira, ter um panorama sobre o atual cenário do construto na academia, oportunizando prospectar os próximos passos da área em termos de desenvolvimento científico. Logo, o objetivo principal da pesquisa é analisar a produção científica, por meio da bibliometria, sobre o turismo gastronômico disponível em bases nacionais e internacionais.

Assim, o trabalho será apresentado, além desta introdução, em mais cinco seções. Neste contexto, na segunda seção serão descritos os principais conceitos que circundam o construto turismo gastronômico, sendo procedido pelo design metodológico que ampara a pesquisa. Logo na sequência serão analisados, apresentados e discutidos os dados coletados. Na penúltima seção ponderase, à luz do objetivo e dos resultados, as conclusões do trabalho. Por fim, são referenciadas as pesquisas que deram suporte científico ao desenvolvimento deste trabalho.

\section{TURISMO GASTRONOMICO}

No entender de Harrington (2005), o conceito de gastronomia possui associação com o ambiente (geografia e clima) e a cultura (história e influências étnicas), prevalecendo os componentes de gosto, sabor e textura de alimentos e bebidas. Neste contexto, Correia et al. (2009) complementam afirmando que os turistas parecem ser atraídos para a experiência do turismo gastronômico por uma combinação de diferente fatores: alguns enfatizam gastronomia e serviços, outros o ambiente e, ainda, a qualidade e o preço. Assim, o reconhecimento de que os turistas procuram diferentes tipos de experiência exige destinos para garantir que o fornecimento de alimentos locais é diversificado e adaptado a 
ISSN: 1983-7151

essas preferências turísticas diferenciadas. Além disso, é claro que o material de comunicação de marketing, tanto no destino como no restaurante, precisa enfatizar esses aspectos diferenciais da experiência gastronômica. De qualquer forma, a alimentação típica pode trazer aos turistas experiências física, cultural, social e de prestígio (Meladze, 2015).

Em complemento, Shlüter \& Ellul (2008) destacam que, se esta gastronomia for orientada ao turista, possivelmente se converterá em popular e atrativa. Logo, a gastronomia pode constituir-se em uma experiência turística como oferta a partir de suas características locais, uma interação com o meio visitado, oportunizando ao turista acesso a uma série de conteúdos simbólicos, história e cultura específicos (Gimenes, 2009; Chiattone \& Chiattone, 2013; Torre \& Rojas, 2015). Desta maneira, a gastronomia torna-se um elemento integrador da infraestrutura turística, seja como um elemento de oferta ou como um fator motivador para a realização da viagem (Bizinelli et al., 2015; Bahls et al., 2015), que pode proporcionar, segundo Santos et al. (2016), experiências turísticas únicas e diferenciadoras.

Por outro prisma Iakovou, Vlachos \& Aidonis (2009) ressaltam que, embora a alimentação destaque-se como um dos elementos essenciais da experiência turística, esta não recebeu a mesma atenção na área de pesquisa acadêmica, em função da formulação de políticas de turismo. Todavia, os autores ainda contextualizam que este cenário está sendo modificado à medida que o significado social e cultural dos alimentos está ganhando reconhecimento, sendo que, desta maneira, o turismo gastronômico surge não apenas como uma atividade econômica autônoma, mas também como um catalisador do desenvolvimento e crescimento regional, visto que complementa e apoia outras formas de turismo e diferentes setores como: agricultura e economia local.

De certa forma, a preocupação de Iakovou et al. (2009), quanto à exclusividade do caráter econômico da atividade de turismo gastronômico, também é fonte de reflexão de Henriques \& Custódio (2010) quando afirmam que, se por um lado este tipo de turismo é reconhecido como patrimônio valorizador da identidade do destino e da experiência do viajante, por outro, o turismo (por meio de terminadas tipologias/segmentos/motivações/comportamentos de 
turistas) pode comprometer a identidade gastronômica, fundamentalmente nas suas dimensões de autenticidade e simbolização. Já Torres \& Gutiérrez (2010) e Teodoroiu (2015) entendem que o turismo gastronômico deve ser visto como fonte potencializadora e peça-chave para o posicionamento dos alimentos regionais, sendo assim uma forma de recuperação da gastronomia local. Além destes aspectos, Krause \& Bahls (2013) destacam que este segmento do turismo também deve ser considerado como influenciador de ações que visam à sustentabilidade ambiental (utilizando produtos locais e de maneira inteligente) e, com isto, contributivo para um custo menor ao planeta.

De qualquer maneira, Oliveira (2011) e Meladze (2015) destacam que o turismo gastronômico é um dos novos produtos turísticos que tem ganhado dimensão nos últimos tempos, bem como despertado a atenção por parte das divulgações das sociedades, fomentando a motivação de viagens em busca da gastronomia e suas pecualiriaridades locais. Para Torre et al. (2011), este cenário evidencia uma mudança de mentalidade do turismo, o qual é cada vez mais exigente em suas preferências e demanda mais um processo de qualidade do segmento. De acordo com os autores, as exigências vão além do serviço que é prestado, incorporando também manutenção dos locais de hospedagem, conservação do entorno, sinalização, outros motivos para a viagem, ou seja, plena satisfação com a experiência.

Assim, o turismo gastronômico pode ser um instrumento para reduzir os principais problemas e desafios que se apresentam nas regiões interioranas. A mudança do tradicional contexto econômico e social para produtora de produtos alimentícios das regiões rurais, por meio de uma estrutura produtiva, poderá oferecer novas oportunidades de trabalho para a população local (Torre \& Morales-Fernández, 2012; Kocaman \& Kocaman, 2014; Ackovska et al., 2015). Torre \& Rojas (2015) e Jeambey (2016) contribuem para a reflexão, afirmando que o turismo gastronômico não está vinculado somente a regiões rurais, mas também às cidades/grandes centros, onde as rotas turísticas têm seu fim ou início.

Seguindo está lógica, Salvo et al. (2013) destacam que o turismo, por meio do desenvolvimento gastronômico, deve ser entendido como uma alternativa 
econômica para cenários de crises, fazendo emergir novos atores, funções, formas de relacionamento e, ainda, novos temas sociais sobre os produtos típicos, o que promove, por contrapartida, o desenvolvimento local. Ampliando esta análise sobre a atratividade econômica do turismo gastronômico, Gordin et al. (2016) grafam que, em contrapartida à concorrência feroz que o mercado de turismo global está experimentando, o desenvolvimento da marca de lugar gastronômico é uma das maneiras de fortalecer a atratividade do destino e superar algumas incertezas do segmento vivência.

Para Hillel et al. (2013) e Sánchez et al. (2014), os membros de um grupo cultural, ao possuírem uma ordem culinária única, externalizam suas características e, com isto, excluem todos os outros. Para os autores é, sem dúvida, este poder simbólico do alimento um marcador de identidade cultural que está no cerne do turismo gastronômico. No entanto, Peccini (2013) destaca que tão importante quanto a alimentação é a informação sobre a mesma. Segundo a autora, a clareza sobre o que será consumido estabelece uma relação de confiança, fundamental no contexto do turismo gastronômico, entre a história e a cultura local, e o turista.

Ampliando o escopo da reflexão, Björk \& Hauppinen-Räisänen (2014) registram que a alimentação regional/típica deve ser entendida como essencial sob diferentes ângulos, não se limitando somente ao turista. Nesse sentido, os autores constataram em pesquisa que a alimentação local é uma importante atração turística e central para a experiência turística, no entanto não é só para aqueles viajantes que têm um interesse especial em alimentos e estão extremamente envolvidos em ganhar experiências gastronômicas, mas também para aqueles que têm uma atitude mais casual para com a refeição/alimentos.

Schwartzhoffová (2014) contribui com a discussão ao incorporar outros aspectos do turismo gastronômico: tours, eventos, aulas e competições. Para a cientista, o turismo gastronômico é uma viagem destinada a explorar a gastronomia, especialmente para provar as delícias culinárias nacionais, entre outras típicas. Ademais, também devem ser considerados como pertencentes ao turismo gastronômico as atividades de visitas a estabelecimentos de alimentação, eventos gastronômicos, aulas de culinária e participação ativa ou 
passiva nas competições gastronômicas. Desta maneira, o turismo gastronômico possui uma amplitude maior do que comumente é considerado.

Assim, a melhor compreensão do turismo gastronômico, além de seus vínculos com o desenvolvimento local e, neste caso específico, do papel desempenhado pelas partes interessadas (stakeholders) e pelas redes que formam, deve contribuir para uma implementação eficaz das estratégias de desenvolvimento nas regiões ou nas comunidades locais, sendo que os alimentos são o meio de melhorar seu status socioeconômico (Londoño, 2015).

Quando analisada a literatura sobre turismo gastronômico e gastronomia, Forné (2016) ensina que esta conjectura é descrita de diferentes formas, como: i) a gastronomia como um produto de atração turística; ii) o comportamento do turista em relação ao consumo de alimentos; o interesse do turista em relação em alimentar-se e beber em qualquer evento e/ou atividades relacionadas. Por certo, segundo o autor, a que mais claramente representa este contexto é a gastronomia como fonte motivadora, principal para a realização de determinada viagem. Assim, o turista "busca conhecer a cultura local por meio de sua gastronomia, através do modo de produção dos alimentos, da origem das receitas dos utensílios e das técnicas de cozinhar, etc." (MARTINS et al., 2016:230).

\section{METODOLOGIA}

A metodologia da pesquisa está amparada na bibliometria. Pritchard (1969) ensina que esta técnica é fundamentada na aplicação de métodos matemáticos e estatísticos sobre o conteúdo de livros e outras mídias de comunicação. Em complemento, Lima (1984) destaca que, embora muitas vezes o desenvolvimento dos cálculos seja relativamente simples, os resultados podem ser surpreendentes.

A consulta foi realizada nas bases de dados: periódicos CAPES, SPELL, PROQUEST, EBSCO. Como descritores-chave foram utilizados: turismo gastronômico, gastronomic tourism e turismo gastronómico. Desta maneira, objetivou-se agregar artigos de idiomas: português, inglês e espanhol. Como 
filtro inicial foram considerados os descritos de diferentes maneiras, em conformidade com as limitações/opções de cada base, ou seja: a) periódicos CAPES: a busca considerou o título das pesquisas; b) PROQUEST: foram considerados os trabalhos com base na associação dos descritos com o resumo dos trabalhos e das publicações revisadas por especialistas; c) EBSCO: foram selecionados os artigos com base nos resumos, textos completos e revistas acadêmicas; e d) SPELL: consideraram-se os resumos dos trabalhos.

Com estes procedimentos foi possível identificar nas bases de dados o total de 94 artigos completos, sendo permitido pelo sistema o download de 87 artigos, visto que muitos não se encontravam com os links para acesso corretos e/ou não existiam os arquivos. Após a comparação entre os textos, verificouse que existiam 26 artigos repetidos, além de 16 sem aderência ao objetivo da pesquisa, visto que o termo turismo gastronômico, em diferentes idiomas, foi utilizado de maneira genérica e/ou simbólica. Desta maneira, para a condução pesquisa considerou-se o total de 45 artigos. No Quadro 1 é possível verificar, de maneira resumida, todas as etapas da busca e da seleção dos artigos.

Quadro 1 - Resumo do processo de busca

\begin{tabular}{|c|c|c|c|c|c|c|}
\hline BASE DE DADOS & DESCRITORES & TOTAL & DOWNLOAD & REPETIDOS & $\begin{array}{c}\text { SEM } \\
\text { ADERÊNCIA }\end{array}$ & TOTAL \\
\hline $\begin{array}{l}\text { Periódicos } \\
\text { CAPES }\end{array}$ & \multirow{4}{*}{$\begin{array}{c}\text { Turismo } \\
\text { Gastronômico } \\
\text { Gastronomic } \\
\text { Tourism } \\
\text { Turismo } \\
\text { Gastronómico }\end{array}$} & 44 & 44 & \multirow{4}{*}{26} & \multirow{4}{*}{16} & \multirow{4}{*}{45} \\
\hline PROQUEST & & 6 & 5 & & & \\
\hline EBSCO & & 24 & 24 & & & \\
\hline SPELL & & 14 & 14 & & & \\
\hline
\end{tabular}

Fonte: Elaboração própria.

As análises dos dados compreenderam diferentes etapas, sendo estas: a) evolução temporal da quantidade de publicações; b) identificação das revistas e das quantidades de publicações; c) realização do cálculo e da interpretação da lei Bradford (1: $n: n^{2}$...) quanto ao core de periódicos; d) identificação dos tipos metodológicos de pesquisa empregados no desenvolvimento dos trabalhos; e) identificação da métrica de centralidade de Freeman para a rede de autores e universidades; f) mensuração do poder de Bonacich para as redes de autores e universidades; g) comparativo com 
o padrão da lei de Lotka $\left(1 / \mathrm{n}^{2}\right)$; h) identificação dos autores e dos trabalhos com maior número de referências; i) verificação das principais palavras utilizadas nos objetivos das pesquisas. Para o tratamento dos dados foram utilizados o softwares: i) numbers, versão 4.0 .5 (4052), para tabulação, organização e cálculos; e; o ii) UcinNet, para desenvolvimento das redes de relacionamentos.

A métrica de centralidade de Freeman indica o quanto o nó se comunica a outros, sendo considerado um elo com muitos grupos (Recuero, 2014). Já a lei de Bradford procura identificar os periódicos mais produtivos ou mais usados (Coutinho, 1988). O poder de Bonacichi é conceituado como sendo aquele nó que está ligado a outros nós que não possuem muitas outras conexões, tornandose um nó muito poderoso/com prestígio, porque os outros dependem dele (Delgado et al., 2009). Sob outro prisma, a lei de Lotka auxilia na investigação da produtividade dos autores. Segundo a teoria, uma grande quantidade da literatura é produzida por um pequeno número de cientistas e uma grande quantidade de pequenos pesquisadores se iguala, em produção, ao reduzido número de grandes cientistas (Araújo, 2006).

\section{ANÁLISE DOS DADOS}

A análise dos dados revelou que, do total de artigos publicados, o maior volume está concentrado nos anos de 2012 e 2015, correspondendo, cada exercício, a 20\% da produção científica. Embora o ano de 2016 represente 8,8\% do total de pesquisas publicadas, tem-se que ressaltar que o levantamento foi realizado no mês de dezembro de 2016, sendo que muitas das revistas não haviam submetido suas publicações, seja por atrasos ou por edições estarem sendo publicadas no final do segundo semestre nas bases de dados consultadas. Assim, acredita-se que a temática esteja sendo considerada nas agendas de pesquisas dos últimos anos, senão de maneira crescente, pelo menos de forma contínua, o que demonstra a relevância deste construto, em especial, para a área de turismo. A evolução da produção científica, com base na amostra estudada, pode ser acompanhada no Gráfico 1. 
Gráfico 1 - Evolução da publicação científica por ano



2005200820092010201120122013201420152016

Fonte: Elaboração própria.

Não obstante a esta ótica, ao serem analisados os canais de publicação das pesquisas, verificou-se que 27 periódicos científicos interessaram-se pela divulgação e pela socialização dessas pesquisas. Verificou-se que os periódicos Passos (Pasos - Revista de Turismo y Patrimônio Cultural - ISSN 1695-7121) e Rosa dos Ventos (Rosa dos Ventos - Turismo e Hospitalidade - ISSN 21789061), originários da Espanha e do Brasil, respectivamente, destacam-se com o número de artigos publicados no período, com o total de 6 pesquisas em cada. Na sequência observou-se que os periódicos Estudios y Perspectivas en Turismo, Tourism \& Managament Studies e TuryDes publicaram 3 pequisas. Já a revista Hospitalidade e a Gran Tour publicaram 2 pesquisas. Nas demais identificou-se apenas 1 pesquisa publicada em cada uma.

Nos periódicos, quando analisados sob o prisma da lei de Bradford, verificase $B n(45 t / 3 g)$. Logo, o core do assunto turismo gastronômico $(B n=15)$ reside nos periódicos: Pasos, Rosa dos Ventos e entre as revistas Estudios y Perspectivas en Turismo, Tourism \& Management Studies e TuryDes. Já os demais são considerados extensões do assunto, segundo a lei de Bradford. Em consulta à base Qualis/CAPES: 2015, na área de administração pública e de empresas, ciências contábeis e turismo, sobre os periódicos core, verificaram-se as seguintes classificações: i) Pasos: Qualis B2; ii) Rosa dos Ventos: Qualis B3; iii) Estudios y Perspectivas en Turismo: Qualis A2; iv) Tourism \& Management Studies: Qualis B1; e; v) TuryDes: Qualis B3.

Estas informações possuem relevância, uma vez que é possível identificar os periódicos que possuem interesse em publicação de pesquisas, logo, poderão 
ser consultados com prioridade, além de ser fonte para submissão de pesquisas por parte dos cientistas.

Ao serem analisados os tipos de pesquisa selecionados pelos pesquisadores para o desenvolvimento dos experimentos científicos, verificou-se que a maioria das pesquisas possuem sua fundamentação na tipologia qualitativa (28 artigos ou $\approx 62,22 \%$ ); na sequência identificou-se a quantitativa (18 artigos ou $\approx 31,11 \%$ ) e, por fim, a qualitativa-quantitativa ( 3 artigos ou $\approx 6,66 \%$ ). Neste mesmo sentido, verificou-se que diferentes técnicas foram empregadas nas pesquisas. Acreditase que o destaque da pesquisa qualitativa se deva ao fato de sua característica de exploração das atividades e das características do turismo gastronômico. Corroborando este posicionamento, verifica-se no Apêndice A que não existem replicações de pesquisas no mesmo objeto, logo, especula-se que os cientistas procuram utilizar este tipo de pesquisa para entender os fenômenos que envolvem o turismo gastronômico e evitam testar diretamente associações, hipóteses, características da pesquisa quantitativa, provavelmente pelos poucos experimentos existentes sobre o construto, quando comparados com outras faces do turismo.

No tocante aos instrumentos utilizados nas pesquisas, quando aplicável, não foi possível identificá-los, apenas em algumas pesquisas as variáveis utilizadas para o levantamento dos dados. A este cenário, excluem-se as pesquisas de Iakovou, Vlachos e Aidonis (2009) e de Jemabey (2016), as quais apresentam os roteiros de perguntas semiestruturadas. A identificação dos instrumentos/ variáveis são relevantes para outros pesquisadores, uma vez que poderão se apoiar nas mesmas para o desenvolvimento de novos experimentos.

Neste contexto, ressalta-se que o detalhamento dos trabalhos, das variáveis utilizadas na pesquisa, do instrumento/variáveis (quando aplicável e disponibilizado), das referências de apoio, do método e dos objetos estudados pode ser visualizado no Apêndice A. Salienta-se que as informações não descritas são decorrentes de falta de informação na pesquisa e/ou não identificadas.

Outra análise desenvolvida durante a execução da pesquisa consistiu na identificação das redes desenvolvidas pelos pesquisadores para o desenvolvimento de seus experimentos científicos. Neste sentido, foi possível identificar a existência de várias parcerias entre os pesquisadores, como pode ser observado na Figura 1. Destaca-se que na imagem os autores são codificados visando à melhor visualização das interações. 
Não obstante, observa-se que, quando mensurado o grau de centralidade de Freeman, o autor Emilio Morales-Fernández (Universidade de Córdoba/Espanha) é destaque, com 7 laços de entrada (ingree) e saída (outgree). Da mesma forma o autor se destaca em função dos resultados aferidos em termos da métrica de poder de Bonacich $\left(C_{i}=28,127\right)$. Com base nas redes e relacionamentos e suas métricas, é possível que outros cientistas interessados no desenvolvimento de pesquisas identifiquem os players que se destacam no cenário científico e, com isto, oportunizando futuras parcerias.

Todavia, embora o Emilio Morales-Fernández receba destaque em termos estatísticos, deve-se reconhecer a importância das demais redes e/ou parcerias formadas para estudar o tema turismo gastronômico, da mesma forma que a não autonomia (únicos autores) em termos de pesquisa de outros 10 autores.

Na sequência realizou-se a comparação do número de trabalhos publicados em função da lei de Lotka. A lógica deste padrão ensina que o percentual de pesquisadores que publica apenas 1 trabalho em determinada área corresponde a $60,79 \%$. A partir deste indicador, outros, na sequência, são assumidos considerando a regra matemática do quadrado inverso. Todos os indicadores são apresentados no Quadro 2, considerando-se autores e coautores. Diante dos resultados verificase que o percentual de autores que publica apenas 1 artigo supera em $35 \%$, o que foi definido como o padrão deste quantitativo de produção. Ressalta-se que o padrão de Lotka apresentou superavitário em todos os indicadores.

Figura 1 - Rede de autores

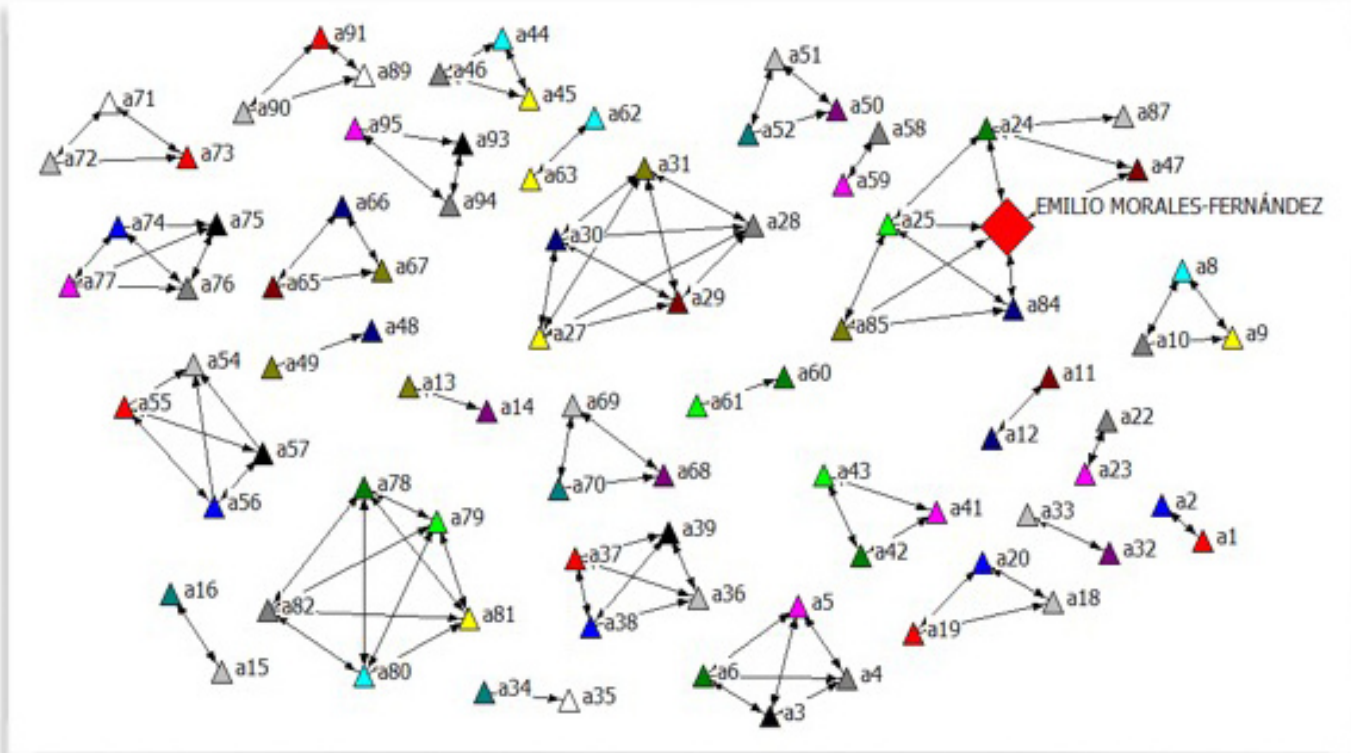

Fonte: Elaboração própria. 
Estes resultados chamam a atenção, sugerindo que muitos autores não seguem pesquisas sobre o turismo gastronômico, produzindo apenas 1 paper. Logo, diante de um cenário deste, deduz-se que muitas oportunidades de densificação, ampliação e exploração da teoria não sejam exploradas.

Quadro 2 - Comparativo lei de Lotka

\begin{tabular}{|c|c|c|c|}
\hline Número de Artigos & Frequência Absoluta & Frequência Relativa & Padrão Lei de Lotka \\
\hline 1 Artigo Publicado & 91 & $95,79 \%$ & $60,79 \%$ \\
\hline 2 Artigos Publicados & 1 & $1,05 \%$ & $15,20 \%$ \\
\hline 3 Artigos Publicados & 1 & $1,05 \%$ & $6,75 \%$ \\
\hline 4 Artigos Publicados & 1 & $1,05 \%$ & $3,80 \%$ \\
\hline 5 Artigos Publicados & 1 & $1,05 \%$ & $2,43 \%$ \\
\hline TOTAL & 95 & $\approx 100 \%$ & - \\
\hline
\end{tabular}

Fonte: Elaboração própria.

Na sequência, a análise dos dados focou na interpretação dos relacionamentos entre universidades para o desenvolvimento de pesquisas. Neste cenário constata-se, conforme Figura 2, que, em comparação com as redes de autores, agora o número de parcerias é menor. Em termos de número de laços, a Universidade de Aveiro torna-se protagonista com 5 laços de entrada e mesmo número de saída (centralidade de Freeman). Logo esta Instituição apresenta-se como sendo a que possui maior número de parcerias. Por outra ótica, quando analisados o poder de Bonacich, a Universidade de Aveiro e a Universidade Loyola Andalucía possuem o mesmo resultado, ou seja, $C_{i}=20,820$. Logo, ambas são consideradas com maior prestígio quando analisadas as redes de suas redes. Todavia as universidades encontram-se desconexas em termos de redes.

Desta maneira, verifica-se que cientistas e/ou profissionais interessados em temáticas associadas diretamente ao turismo gastronômico possivelmente encontrarão grupos de pesquisa nestas universidades interessados no debate e/ou desenvolvimento de novas pesquisas, além de serem referência em termos de relacionamentos com outras universidades. Outro aspecto que se destaca é que ambas estão localizadas no continente europeu (Portugal e Espanha), respectivamente.

Grafa-se que outras 19 universidades foram identificadas como não realizando parcerias para o desenvolvimento de suas pesquisas sobre o construto turismo gastronômico, sendo estas: University of Guelph; Universidade Federal do 
Paraná; Aristotle University of Thessaloniki; Universidade Estadual de Santa Cruz; University of Barcelona; Instituto Politécnico de Leiria; Universidad de Oriente; University of Deusto; Universidade Federal de Pelotas; Ben-Gurion University of the Negev; Arquivo Histórico João Spadari Adami; Hanken School of Economics; Gaziosmanpaşa University; Palacký University Olomouc; Universidade do Vale do Itajaí; Grigol Robakidze University; The Bucharest University of Economic Studies; Universitat de Girona; e University Higher School of Economics.

Figura 2 - Rede de universidades

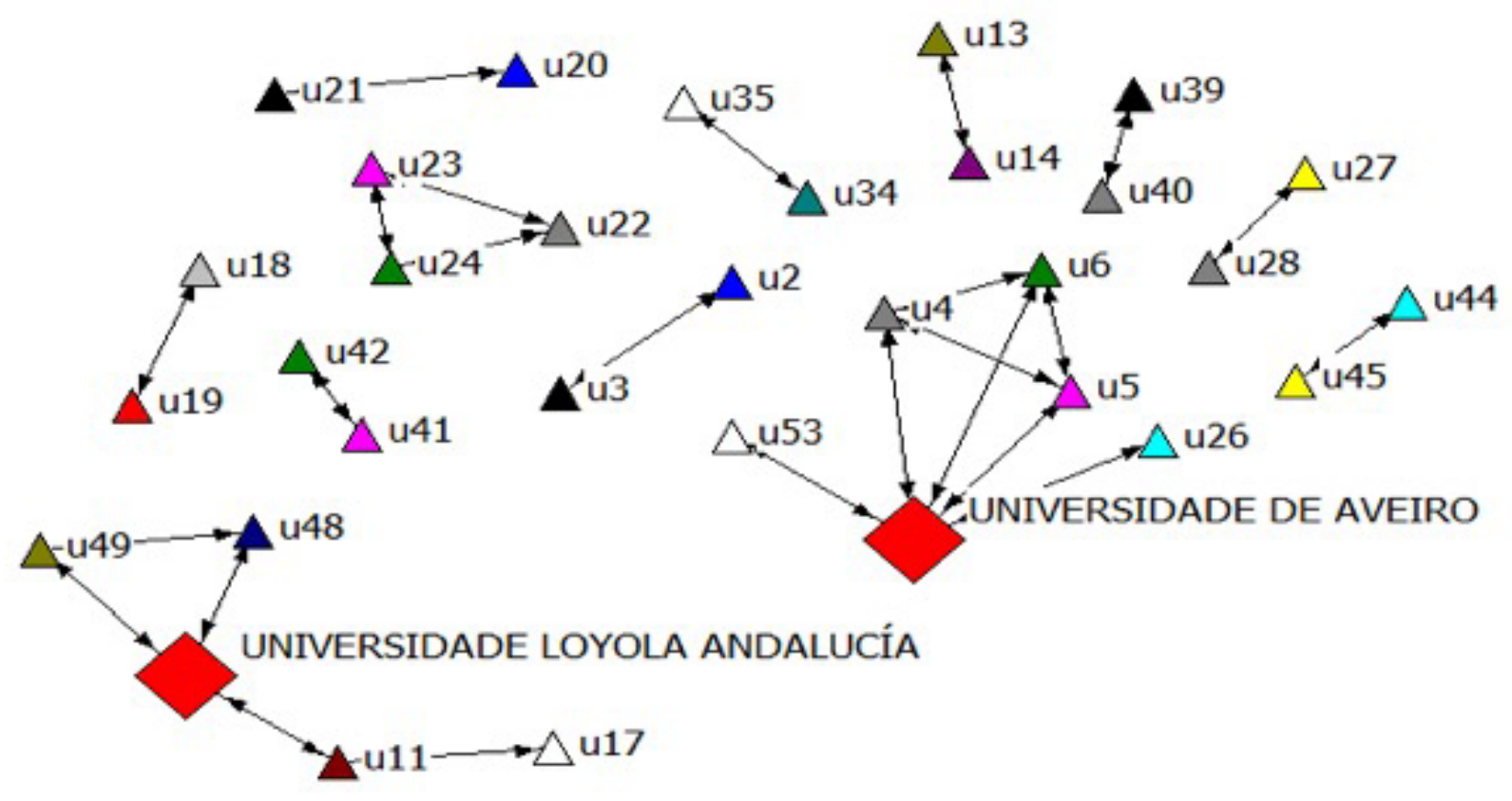

Fonte: Elaboração própria.

Outra análise realizada se referiu às referências utilizadas pelos pesquisadores no desenvolvimento de suas pesquisas. Para tanto a interpretação considerou somente o primeiro autor referenciado. Após a tabulação de 1.465 referências, foi possível verificar os 12 autores mais referenciados, como pode ser observado no Quadro 3. Dentre os autores com maior número de citações, Michael Hall se destaca, sendo referenciado 41 (2,79\%) vezes. O trabalho com maior número de referências é o de Erik Cohen, que foi referenciado 12 (0,81\%) vezes, seguido da pesquisa de Jaksa Kivela, apontada 11 (0,75\%) vezes.

Esta informação se torna importante na medida em que futuras pesquisas possuam como o direcionamento de quais são as pesquisas consideradas como sendo balizares na fundamentação na construção científica do turismo gastronômico. 
Quadro 3 - Autores e respectivas pesquisas mais referenciados

\begin{tabular}{|c|c|c|c|}
\hline AUTOR & CIT. & PESQUISA & CIT. \\
\hline Hall, M. & 41 & $\begin{array}{l}\text { Food tourism around the World: Development, Management and } \\
\text { Markets }\end{array}$ & 9 \\
\hline Hjalager, A. M. & 20 & Tourism and gastronomy & 10 \\
\hline Kivela, J. & 16 & $\begin{array}{c}\text { Tourism and gastronomy: Gastronomy's influence on how tourists } \\
\text { experience a destination }\end{array}$ & 11 \\
\hline Millán, G. & 16 & $\begin{array}{c}\text { El oleoturismo como motor de desarrollo rural. La denominación de } \\
\text { origen de montoro-adamuz }\end{array}$ & 5 \\
\hline Cohen, E. & 12 & Food in tourism: Attraction and impediment & 12 \\
\hline Schluter, R. & 12 & $\begin{array}{c}\text { Gastronomia e turismo; Turismo y patrimonio gastronómico - Una } \\
\text { perspectiva }\end{array}$ & 4 \\
\hline Richards, G. & 11 & $\begin{array}{l}\text { Gastronomy: an essential ingredient in tourism production and } \\
\text { consumption? }\end{array}$ & 8 \\
\hline Barrera, E. & 11 & $\begin{array}{l}\text { Turismo Rural: Nueva ruralidad y Empleo rural no agrícola; Las rutas } \\
\text { alimentarias: una arquitectura turistica basada en la identidad de los } \\
\text { alimentos }\end{array}$ & 3 \\
\hline Oliveira, S. & 9 & $\begin{array}{l}\text { La gastronomía como atractivo turístico primario de un destino. Un } \\
\text { ejemplo de Mealhada, Portugal }\end{array}$ & 3 \\
\hline Quan, S. & 8 & $\begin{array}{l}\text { Towards a structural model of the tourist experience: an illustration from } \\
\text { food experiences in tourism }\end{array}$ & 8 \\
\hline Long, L. M. & 8 & Culinary Tourism: a folkloristic perspective on eating and otherness & 5 \\
\hline Santich, B. & 8 & $\begin{array}{l}\text { The study of gastronomy and its relevance to hospitality education and } \\
\text { training }\end{array}$ & 4 \\
\hline
\end{tabular}

Fonte: Elaboração própria.

Objetivando confrontar os interesses das pesquisas exploradas com a temática em discussão, realizou-se uma nuvem de palavras utilizando os objetivos destas e verificando quais são as palavras com maior proeminência. Nestas atividades, foram mantidas as frases no idioma em que foram publicadas. Assim, conforme pode ser observado na Figura 3, as palavras turismo, gastronomia, desenvolvimento, objetivo, em diferentes idiomas, destacam-se.

A nuvem de palavras apontou para a convergência entre as pesquisas selecionadas e o objetivo principal deste experimento, visto que as palavras turismo, gastronomia, desenvolvimento, em diferentes idiomas, apresentaramse em destaque e, com isto, também sugere quais são os construtos que são considerados nas pesquisas. 
Figura 3 - Nuvem de palavras contidas nos objetivos das pesquisas
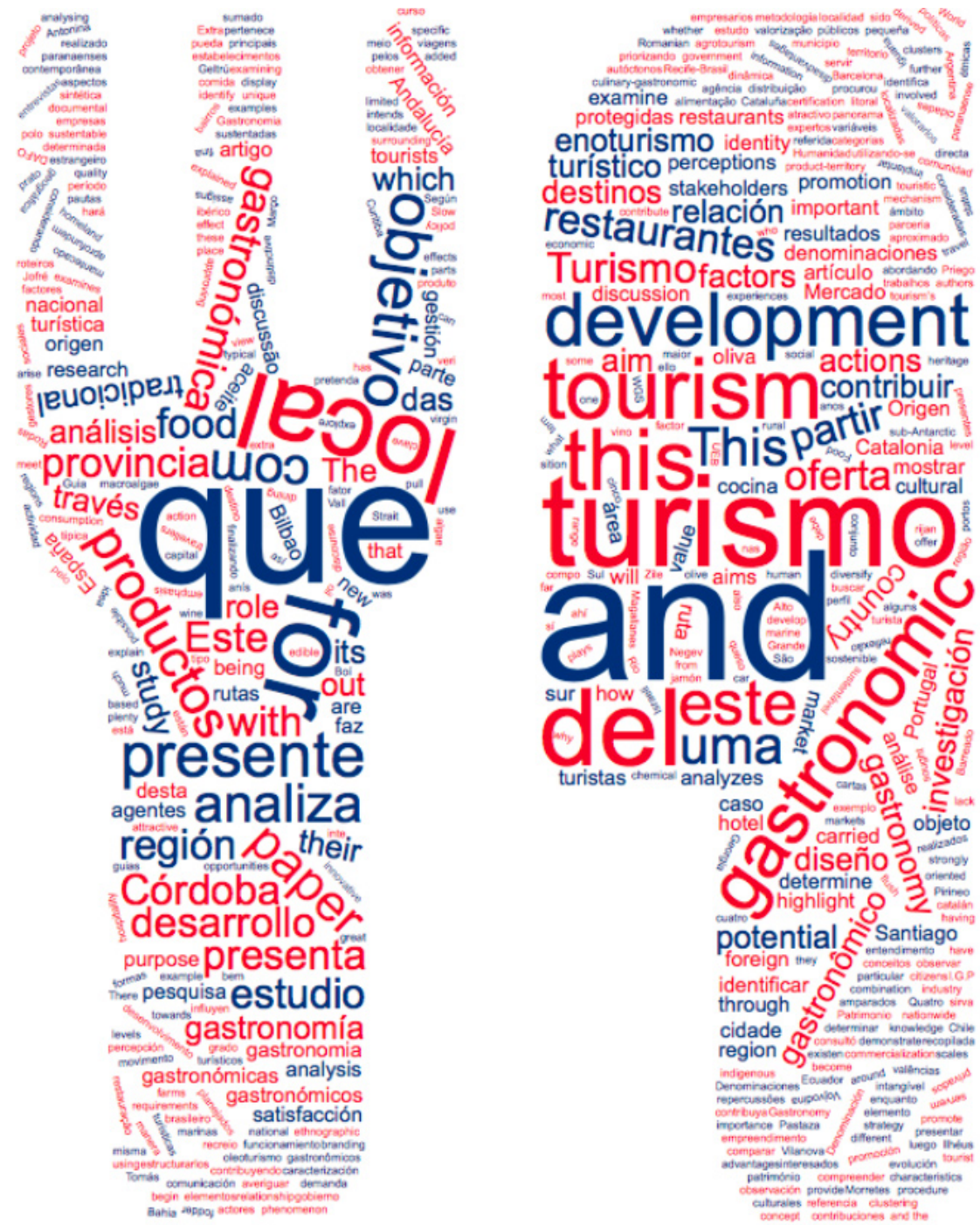

Fonte: Elaboração própria.

Diante das ponderações anteriores, na sequência serão apresentadas as considerações finais sobre a pesquisa, bem como as limitações e as sugestões para agendas de pesquisa interessadas na temática.

\section{CONSIDERAÇÕES FINAIS}

Tendo em vista o objetivo inicial da pesquisa de analisar a produção científica por meio da bibliometria sobre turismo gastronômico disponível em bases nacionais e internacionais, considera-se que este foi plenamente atingido. Neste contexto, não é possível afirmar se as pesquisas sobre a temática estão em acensão ou declínio. Muito embora o ano de 2015 tenha sido um dos mais proeminentes em termos de volume de artigos publicados, o ano de 2016 teve uma queda de $55 \%$ na quantidade de pesquisas. Estes resultados não podem 
ser considerados como um declínio no interesse de pesquisas em função da possibilidade de muitas bases não terem sido atualizadas com as publicações do segundo semestre de 2016.

Por outra ótica, foi verificado que apenas 4,2\% dos pesquisadores produziram mais de um artigo no período. Os resultados chamam a atenção, uma vez que possibilitam especular que as pesquisas não possuem continuidade e, desta forma, muitas vezes deixam à margem experimentos sobre o turismo gastronômico, incorporando diferentes prismas de análise. Este cenário é contrastado pela existência de várias redes de pesquisadores e universidades.

Dentre outras conclusões obtidas com o desenvolvimento da pesquisa, verificou-se que o construto turismo gastrônomico é reconhecido pela sua importância em diferentes aspectos, sendo estes: i) econômico: poder de fomentar recursos econômicos para rotas e regiões por meio de aporte financeiro de turistas quando das suas viagens; e ii) social/cultural: ressurgimento/ manutenção de receitas/hábitos culturais típicos das localidades e/ou de ancestrais. Ainda, o contexto é visto como alternativa para a manutenção de propriedades rurais, implementando atividade acessória a principal.

Não obstante, quando o turismo gastronômico não é implementado e/ou executado com responsabilidade, muitas consequências negativas também são ressaltadas, como a exploração econômica das comunidades; desvirtuação dos valores originais; geração de cinturões de pobreza no entorno, entre outros. Logo, o turismo gastronômico é uma atividade considerada importante, mas, como outras, deve ser desenvolvida com estratégia, planejamento e responsabilidade, principalmente com relação às pessoas e à sua história.

Todavia, o turismo gastronômico é reconhecido pelos cientistas como sendo uma oportunidade para o desenvolvimento local e regional com ações que já são tradicionalmente executadas, porém muitas vezes pouco divulgadas, como pratos típicos elaborados a partir de receitas e ingredientes específicos de determinada população, como os queijos de Vall de Boí na Espanha; os pratos indígenas, campesinos e tradicionais de Cuenca Alta Del Rio Lerma no México; além do barreado no Paraná/Brasil, entre outros. 
Reconhece-se que a pesquisa possui algumas limitações, que não desmerecem os resultados identificados, mas que devem ser ponderadas. Dentre estas, o fato das bases de dados serem alimentadas com frequência limita o número de artigos selecionados, correndo o risco de outras pesquisas, também relevantes, não serem identificadas. Ainda muitas metodologias dos trabalhos não apresentavam o delineamento detalhado das atividades, o que limitou o aprofundamento dos procedimentos utilizados nas pesquisas.

Não obstante, acredita-se que a replicação deste experimento em futuras agendas de pesquisa buscando a atualização dos achados seja salutar para o entendimento da área. Ademais, a inclusão na atividade de busca de artigos oriundos de revistas que não estejam indexadas nas bases de dados é recomendada para novas pesquisas. Ainda, estimula-se que em futuras pesquisas cientistas considerem analisar as redes de pesquisadores coautores nas publicações.

\section{REFERÊNCIAS}

Ackovska, M.; Petroska-Angelovska, N. \& Magdinceva-Sopova, M. (2015). Possibilities for development of agro-tourism and gastronomic tourism in the Republic of Macedonia. Economic Development, 3, 47-62.

Araújo, C. A. (2006). Bibliometria: evolução histórica e questões atuais. Em questão, 12(1), 11-32.

Bahls, A. A.; Krause, R. W. \& Farias, F. S. (2015). Planejamento gastronômico em destinos turísticos: uma comparação entre o panorama nacional e o estrangeiro. Rosa dos Ventos, $7(2), 223-241$.

Bizinelli, C.; Manosso, F. C.; Abrahão, C. M. S. \& Gândara, J. M. G. (2016). A Curitiba dos restaurantes: uma análise da evolução dos estabelecimentos de alimentação comercial com base nos registros do Guia Quatro Rodas - 1989/2014. Revista Hospitalidade, 13, 8-28.

Björk, P. \& Kauppinen-Räisänen, H. (2014). Culinary-gastronomic tourism - a search for local food experiences. Nutrition \& Food Science, 44(4), 294-309.

Chiattone, M. V. \& Chiattone, P. V. (2013). Enoturismo: atrativo e ferramenta para o desenvolvimento sustentável de regiões. Rosa dos Ventos, 5(4), 616-634. 
Correia, A.; Moital, M.; Oliveira, N. \& Costa, C. F. (2009). Multidimensional segmentation of gastronomic tourists based on motivation and satisfaction, International Journal of Tourism Policy, 2(1/2).

Coutinho, E. (1988). As armadilhas da lei de Bradford. Revista de Biblioteconomia, 16(2), 217-225.

Delgado, S. S.; Santos, S. R. S. \& Côrtes, M. R. (2009). Mapeamento da rede egocêntrica de uma empresa automobilística e seus fornecedores, através da análise de redes sociais: aspectos de cooperação, de confiança, de centralidade e de poder. Proceedings XXIX Encontro Nacional de Engenharia de Produc, ão, Salvador, BA.

Forné, F. F. (2016). El queso como recurso turístico para el desarrollo regional: la Vall de Boí como caso de estúdio. Pasos - Revista de Turismo y Patrimonio Cultural, 14(1), 243-251.

Gimenes, M. H. G., (2009). Turismo à mesa: da oferta contemporânea do barreado no litoral paranaense. Turismo e Análise, 20 (3), 485-503.

Gordin, V.; Trabskaya, J. \& Zelenskaya, E. (2016). The role of hotel restaurants in gastronomic place branding. International Journal of Culture, Tourism and Hospitality Research, 10 (1), 81-90.

Harrington, R. J. (2005). Food and wine commentary. Journal of Culinary Science \& Technology, $4(2 / 3), 129-152$.

Henriques, C. \& Custódio, M. J. (2010). Turismo e gastronomia: a valorização do património gastronómico na região de Algarve. Tourism \& Management Studies, 6, 69-81.

Hillel, D.; Belhassen, Y. \& Shani, A. (2013). What makes a gastronomic destination attractive? Evidence from the Israel Negev. Tourism Management, 36, 200-209.

Iakavou, E.; Vlachos, D. \& Aidonis, D. (2009). A strategic methodological framework for the development of gastronomic tourism: a Greek region's experience. International Journal of Innovation and Regional Development, 1(3), 301-318.

Jeambey, Z. (2016). Rutas gastronómicas y desarrollo local: un ensayo de conceptualización en Cataluña. Pasos - Revista de Turismo y Patrimonio Cultural, 14 (5), 1187-1198.

Kocaman, M. \& Kocaman, E. M. (2014). The importance of cultural and gastronomic tourism in local economic development: Zile Sample. International Journal of Economics and Financial Issues, 4(4), 735-744.

Krause, R. W. \& Bahls, A. A. D. S. M. (2013). Orientações gerais para uma gastronomia sustentável. Revista Turismo e Ação, 15(3), 434-450. 
Londoño, M. L. (2015). Promoting gastronomic tourism to foster local development: the stakeholder's perspective. AlmaTourism, 11, 54-74.

Martins, U. M. O.; Gurgel, L. I. \& Martins, J. C. O. (2016). Experiências com gastronomia local: um estudo de caso sobre movimento slow food e o turismo gastronômico na cidade de Recife-Brasil. Pasos - Revista de Turismo y Patrimonio Cultural, 14(1), 229-241.

Meladze, M. (2015). The importance of the role of local food in Georgian tourism. European Scientific Journal, 2, 222-227.

Oliveira, S. (2011). La gastronomía como atractivo turístico primario de un destino: el turismo gastronómico en Mealhada - Portugal. Estudios y Perspectivas en Turismo, 20, 738-752.

Peccini, R. (2013). A gastronomia e o turismo. Rosa dos Ventos, 5(2), 206-217.

Recuero, R. (2014). Métricas de centralidade e conversações em redes sociais na internet: desvelando estratégias nos debates presidenciais de 2014. Proceedings VIII Simpósio Nacional da ABCiber, São Paulo, SP.

Salvo, P.; Mogollón, J. M. H.; Clemente, E. D. \& Calzati, V. (2013). Territory, tourism and local products. The extra virgin oil's enhancement and promotion: a benchmarking Italy-Spain. Tourism and Hospitality Management, 19(1), 23-34.

Sánchez, L. R. F.; Aguilera, D. S. \& Manfugás, J. M. E. (2014). La comida típica amazónica, una alternativa para el desarrollo del turismo gastronómico. Caso de estudio: Puyo, Pastaza, Ecuador. Revista Turismo e Desarollo Local, 7(17), 1-15.

Santos, J. T., Pinto, P. S. L. G. S. \& Guerreiro, M. (2016). O contributo da experiência gastronómica para o enriquecimento da experiência turística. Perspectivas do estudo no Algarve, Portugal. Revista Turismo - Visão e Ação, 18(3), 498-527.

Schwartzhoffová, E. (2014). Select events as a special product of gastrotourism in the Czech Republic. Czech Hospitality \& Tourism Papers, 10(21), 62-72.

Shlüter, R. G. \& Ellul, D. T. (2008). Gastronomía y turismo en Argentina polo gastronómico Tomás Jofré. Pasos - Revista de Turismo y Patrimonio Cultural, 6(2), 249-268.

Silveira-Martins, E., Zonatto, V. C. S. (2015). Proposição e validação de escala para mensuração de capacidade turística. Revista Turismo em Análise, 26(4), 745-773.

Siveira-Martins, E., Zonatto, V. C. S., Mascarenhas, L. E. (2016). Capacidade turística como pressuposto de desempenho organizacional: um estudo no setor hoteleiro. Tourism \& Management Studies, 12(2), 47-56. 
Teodoroiu, F. (2015). Traditional food. Case study: Romanian local food. Review of International Comparative Management, 16(2), 256-268.

Torre, M G. M. V. \& Rojas, R. D. H. (2015). Análisis de la oferta en restauración de la ciudad de Córdoba y su implicación con las rutas gastronómicas de la provincia. Revista de Turismo y Desarrollo Local, 8(18).

Torre, M. G. M. V. L.; Castro-Freire, M. S. \& Morales-Fernandez, E. J. (2011). El turismo rural en Andalucía: un análisis FODA. Rosa dos Ventos, 3(3), 303-323.

Torre, M. G. M. V. L. \& Morales-Fernández, E. J. (2012). Denominaciones de origen protegidas (D.O.P.) y turismo gastronómico: una relación simbiótica en Andalucía. Gran Tour: Revista de Investigaciones Turísticas, 6, 101-121.

Torre, M. G. M. V. \& Gutiérrez, E. M. A., (2010). El turismo gastronómico y las denominaciones de origen en el sur de España: oleoturismo. un estudio de caso. Pasos - Revista de Turismo y Patrimonio Cultural, 8(1), 91-112.

\section{APÊNDICE A}

\begin{tabular}{|c|c|c|c|c|c|}
\hline Pesquisa & Variáveis & Instrumento & $\begin{array}{l}\text { Referências de } \\
\text { Apoio }\end{array}$ & Método & Objeto \\
\hline $\begin{array}{l}\text { Harrington } \\
\text { (2005) }\end{array}$ & $\begin{array}{c}\text { Cultura, } \\
\text { ambiente e } \\
\text { identidade } \\
\text { gastronômica }\end{array}$ & - & - & $\begin{array}{c}\text { Qualitativa/Revisão } \\
\text { Teórica }\end{array}$ & - \\
\hline $\begin{array}{l}\text { Schlüter \& } \\
\text { Ellul (2008) }\end{array}$ & História & $\begin{array}{c}\text { Algumas } \\
\text { perguntas } \\
\text { encontram-se } \\
\text { na metodologia } \\
\text { do trabalho } \\
\text { (p.257) }\end{array}$ & - & $\begin{array}{c}\text { Qualitativa/Estudo } \\
\text { de caso }\end{array}$ & $\begin{array}{c}\text { Polo } \\
\text { gastronômico } \\
\text { Tomás Jofré }\end{array}$ \\
\hline $\begin{array}{l}\text { Gimenes } \\
(2009)\end{array}$ & $\begin{array}{c}\text { Oferta } \\
\text { comercial e } \\
\text { desenvolvimento } \\
\text { turístico }\end{array}$ & - & - & $\begin{array}{c}\text { Qualitativa/Estudo } \\
\text { de caso }\end{array}$ & $\begin{array}{l}\text { Barreado (prato } \\
\text { tradicional } \\
\text { estado do } \\
\text { Paraná) }\end{array}$ \\
\hline $\begin{array}{c}\text { Iakovou et al. } \\
\text { (2009) }\end{array}$ & $\begin{array}{c}\text { Pontos } \\
\text { fracos, fortes, } \\
\text { oportunidades e } \\
\text { ameaças }\end{array}$ & $\begin{array}{c}\text { Roteiro de } \\
\text { perguntas } \\
\text { semiestruturada } \\
\text { (p. 307) }\end{array}$ & - & $\begin{array}{l}\text { Qualitativa/ } \\
\text { Exploratório }\end{array}$ & $\begin{array}{l}\text { Região central } \\
\text { da Macedônia } \\
\text { (Grécia) }\end{array}$ \\
\hline
\end{tabular}




\begin{tabular}{|c|c|c|c|c|c|}
\hline Pesquisa & Variáveis & Instrumento & $\begin{array}{l}\text { Referências de } \\
\text { Apoio }\end{array}$ & Método & Objeto \\
\hline $\begin{array}{l}\text { Correia et al. } \\
\text { (2009) }\end{array}$ & $\begin{array}{l}\text { Motivação e } \\
\text { satisfação }\end{array}$ & $\begin{array}{c}\text { As varáveis } \\
\text { podem ser } \\
\text { identificadas } \\
\text { nas análises dos } \\
\text { dados }\end{array}$ & $\begin{array}{l}\text { Auty (1992); } \\
\text { Gregoire et } \\
\text { al., (1995); } \\
\text { Clark e Wood } \\
\text { (1992); Kivela } \\
\text { et al. (1999); } \\
\text { MacLaurin e } \\
\text { MacLaurin } \\
\text { (2000); Weiss } \\
\text { et al. (2004); } \\
\text { Maio e Olson } \\
\text { (1994) }\end{array}$ & Quantitativa/Survey & $\begin{array}{l}\text { Turistas durante } \\
\text { visita a Portugal }\end{array}$ \\
\hline $\begin{array}{l}\text { Henriques } \\
\text { \& Custódio } \\
\text { (2010) }\end{array}$ & $\begin{array}{c}\text { Valorização } \\
\text { da identidade } \\
\text { gastronômica }\end{array}$ & $\begin{array}{c}\text { As variáveis } \\
\text { podem ser } \\
\text { identificadas } \\
\text { nas análises dos } \\
\text { dados }\end{array}$ & - & $\begin{array}{c}\text { Quantitativa/Análise } \\
\text { de conteúdo }\end{array}$ & $\begin{array}{c}\text { Restaurantes de } \\
\text { Algarve }\end{array}$ \\
\hline $\begin{array}{c}\text { Torre \& } \\
\text { Gutiérrez } \\
(2010)\end{array}$ & $\begin{array}{l}\text { Rotas turísticas, } \\
\text { denominação de } \\
\text { origem, olivas }\end{array}$ & - & - & Quantitativa/Survey & $\begin{array}{c}\text { Rota do óleo em } \\
\text { Espanha }\end{array}$ \\
\hline $\begin{array}{l}\text { Cruz et al. } \\
\text { (2010) }\end{array}$ & $\begin{array}{c}\text { Patrimônio } \\
\text { cultural } \\
\text { gastronômico }\end{array}$ & - & - & $\begin{array}{c}\text { Qualitativa/Revisão } \\
\text { Teórica }\end{array}$ & - \\
\hline $\begin{array}{l}\text { Londoño } \\
\text { (2010) }\end{array}$ & $\begin{array}{c}\text { Desenvolvimento } \\
\text { local }\end{array}$ & - & - & $\begin{array}{l}\text { Qualitativa/análise } \\
\text { de conteúdo }\end{array}$ & $\begin{array}{l}\text { Público em geral } \\
\text { e acadêmicos } \\
\text { sobre o turismo } \\
\text { gastronômico } \\
\text { da Catalúnia }\end{array}$ \\
\hline $\begin{array}{l}\text { Londoño } \\
\text { (2011) }\end{array}$ & $\begin{array}{l}\text { Planejamento, } \\
\text { análise swot }\end{array}$ & - & - & Qualitativa & $\begin{array}{l}\text { Mercados } \\
\text { municipais } \\
\text { de Vila Nova } \\
\text { e Geltriu - } \\
\text { Espanha }\end{array}$ \\
\hline $\begin{array}{l}\text { Medeiros et } \\
\text { al. (2011) }\end{array}$ & Fenomenologia & - & - & $\begin{array}{c}\text { Qualitativa/Revisão } \\
\text { Teórica }\end{array}$ & - \\
\hline $\begin{array}{l}\text { Oliveira } \\
\text { (2011) }\end{array}$ & $\begin{array}{c}\text { Turismo } \\
\text { gastronômico }\end{array}$ & - & - & Quali/Quanti & $\begin{array}{c}\text { Turistas de } \\
\text { Mealha/Portugal }\end{array}$ \\
\hline $\begin{array}{l}\text { Pérez \& Días } \\
\text { (2011) }\end{array}$ & $\begin{array}{c}\text { Modelo de } \\
\text { benchmarking }\end{array}$ & - & - & Quantitativa/Survey & $\begin{array}{c}\text { Sucursal } \\
\text { Extrahotelera } \\
\text { Palmares S/A } \\
\text { - Santiago de } \\
\text { Cuba/Cuba }\end{array}$ \\
\hline $\begin{array}{l}\text { Torre et al. } \\
\quad(2011)\end{array}$ & $\begin{array}{l}\text { Turismo rural, } \\
\text { pontos fortes, } \\
\text { pontos fracos, } \\
\text { oportunidades e } \\
\text { ameaças }\end{array}$ & - & - & $\begin{array}{c}\text { Qualitativa/Estudo } \\
\text { de Caso }\end{array}$ & $\begin{array}{l}\text { Região de } \\
\text { Andaluzia/ } \\
\text { Espanha }\end{array}$ \\
\hline
\end{tabular}


Dor: 10.14210/rtva.v20n4.p184-208

\begin{tabular}{|c|c|c|c|c|c|}
\hline Pesquisa & Variáveis & Instrumento & $\begin{array}{l}\text { Referências de } \\
\text { Apoio }\end{array}$ & Método & Objeto \\
\hline Jiang (2012) & $\begin{array}{c}\text { Turismo } \\
\text { gastronômico, } \\
\text { pontos fortes, } \\
\text { pontos fracos, } \\
\text { oportunidades e } \\
\text { ameaças }\end{array}$ & - & $\begin{array}{l}\text { Vázquez } \\
\text { (2005) }\end{array}$ & Quali/Quanti & Bilbao/Espanha \\
\hline $\begin{array}{c}\text { Carrieri et al. } \\
\text { (2012) }\end{array}$ & $\begin{array}{l}\text { Hábitos } \\
\text { alimentares } \\
\text { e turismo } \\
\text { gastronômico }\end{array}$ & - & - & $\begin{array}{l}\text { Qualitativa/análise } \\
\text { do discurso }\end{array}$ & $\begin{array}{c}\text { Mercado } \\
\text { Central de } \\
\text { Santiago (Chile) } \\
\text { e Mercado } \\
\text { Municipal de } \\
\text { São Paulo } \\
\text { (Brasil) }\end{array}$ \\
\hline $\begin{array}{c}\text { Chaney \& } \\
\text { Ryan (2012) }\end{array}$ & $\begin{array}{c}\text { Turismo } \\
\text { gastronômico e } \\
\text { desenvolvimento } \\
\text { local }\end{array}$ & - & - & $\begin{array}{l}\text { Qualitativa/ } \\
\text { Descritiva }\end{array}$ & $\begin{array}{l}\text { World Gourmet } \\
\text { Summit/ } \\
\text { Singapura }\end{array}$ \\
\hline $\begin{array}{c}\text { Castro \& } \\
\text { Santos (2012) }\end{array}$ & $\begin{array}{l}\text { Turismo, cultura, } \\
\text { identidade, } \\
\text { patrimônio e } \\
\text { gastronomia }\end{array}$ & - & - & $\begin{array}{c}\text { Qualitativa/análise } \\
\text { documental }\end{array}$ & $\begin{array}{l}\text { Restaurantes de } \\
\text { Aracajú/Sergipe }\end{array}$ \\
\hline $\begin{array}{l}\text { Contreras et } \\
\text { al. (2012) }\end{array}$ & $\begin{array}{l}\text { Gastronomia } \\
\text { local e suas } \\
\text { identidades }\end{array}$ & - & - & $\begin{array}{l}\text { Qualitativa/ } \\
\text { Etnografia }\end{array}$ & $\begin{array}{l}\text { Gastronomia } \\
\text { regional de } \\
\text { Cuenca del Alto } \\
\text { Lerma (México) }\end{array}$ \\
\hline $\begin{array}{l}\text { Martins et al. } \\
\text { (2012) }\end{array}$ & $\begin{array}{l}\text { Publicidade } \\
\text { (brochuras) }\end{array}$ & - & - & $\begin{array}{c}\text { Qualitativa/análise } \\
\text { documental }\end{array}$ & $\begin{array}{c}\text { Diferentes } \\
\text { destinos do } \\
\text { Brasil }\end{array}$ \\
\hline $\begin{array}{l}\text { Torre \& } \\
\text { Morales- } \\
\text { Fernández } \\
(2012)\end{array}$ & $\begin{array}{c}\text { Certificação } \\
\text { de origem, } \\
\text { pontos fortes, } \\
\text { pontos fracos, } \\
\text { oportunidades e } \\
\text { ameaças }\end{array}$ & - & - & $\begin{array}{c}\text { Qualitativa/Estudo } \\
\text { de Caso }\end{array}$ & $\begin{array}{l}\text { Região de } \\
\text { Andaluzia/ } \\
\text { Espanha }\end{array}$ \\
\hline $\begin{array}{l}\text { Torre et al. } \\
\text { (2012) }\end{array}$ & $\begin{array}{c}\text { Turismo } \\
\text { gastronômico }\end{array}$ & - & - & Quantitativa/Survey & $\begin{array}{c}\text { Rotas } \\
\text { Gastronômicas } \\
\text { de Córdoba } \\
\text { (Espanha) }\end{array}$ \\
\hline $\begin{array}{l}\text { Martínez et } \\
\text { al. (2012) }\end{array}$ & \begin{tabular}{|c|} 
Satisfação dos \\
turistas sobre os \\
alimentos
\end{tabular} & - & - & Quali/Quanti & $\begin{array}{l}\text { Bernidorm/ } \\
\text { Espanha }\end{array}$ \\
\hline $\begin{array}{c}\text { Chiattone \& } \\
\text { Chiatonne } \\
(2013)\end{array}$ & $\begin{array}{c}\text { Turismo } \\
\text { gastronômico e } \\
\text { enoturismo }\end{array}$ & - & - & $\begin{array}{c}\text { Qualitativa/Revisão } \\
\text { Teórica }\end{array}$ & $\begin{array}{l}\text { Serra Gaúcha/ } \\
\text { Rio Grande do } \\
\text { Sul (Brasil) }\end{array}$ \\
\hline $\begin{array}{l}\text { Hillel et al. } \\
\text { (2013) }\end{array}$ & $\begin{array}{c}\text { Turismo } \\
\text { gastronômico e } \\
\text { desenvolvimento } \\
\text { local }\end{array}$ & - & - & $\begin{array}{l}\text { Qualitativa/ } \\
\text { Exploratório }\end{array}$ & $\begin{array}{l}\text { Israeli Negev } \\
\text { (Israel) }\end{array}$ \\
\hline Peccini (2013) & $\begin{array}{l}\text { Gastronomia e } \\
\text { alimentação }\end{array}$ & - & - & $\begin{array}{c}\text { Qualitativa/Revisão } \\
\text { Teórica }\end{array}$ & - \\
\hline
\end{tabular}




\begin{tabular}{|c|c|c|c|c|c|}
\hline Pesquisa & Variáveis & Instrumento & $\begin{array}{l}\text { Referências de } \\
\text { Apoio }\end{array}$ & Método & Objeto \\
\hline $\begin{array}{l}\text { Salvo et al. } \\
\text { (2013) }\end{array}$ & $\begin{array}{l}\text { Produtos locais, } \\
\text { turismo e } \\
\text { desenvolvimento }\end{array}$ & - & - & $\begin{array}{c}\text { Qualitativa/Revisão } \\
\text { Teórica }\end{array}$ & Itália e Espanha \\
\hline $\begin{array}{l}\text { Kocaman \& } \\
\text { Kocaman } \\
(2014)\end{array}$ & $\begin{array}{c}\text { Turismo } \\
\text { gastronômico e } \\
\text { desenvolvimento } \\
\text { local }\end{array}$ & - & - & $\begin{array}{l}\text { Qualitativa/ } \\
\text { Exploratório }\end{array}$ & $\begin{array}{l}\text { Distrito de Zile } \\
\text { (Turquia) }\end{array}$ \\
\hline $\begin{array}{l}\text { Astorga- } \\
\text { España \& } \\
\text { Mansilla } \\
(2014)\end{array}$ & $\begin{array}{c}\text { Turismo } \\
\text { gastronômico }\end{array}$ & - & - & $\begin{array}{l}\text { Quantitativa/ } \\
\text { Experimental }\end{array}$ & $\begin{array}{l}\text { Região de } \\
\text { Magallanes } \\
\text { (Chile) }\end{array}$ \\
\hline $\begin{array}{c}\text { Björk \& } \\
\text { Kauppinen- } \\
\text { Räisänen } \\
\text { (2014) }\end{array}$ & $\begin{array}{c}\text { Culinária } \\
\text { e turismo } \\
\text { gastronômico }\end{array}$ & $\begin{array}{c}\text { As variáveis } \\
\text { podem ser } \\
\text { identificadas } \\
\text { nas análises dos } \\
\text { dados }\end{array}$ & $\begin{array}{l}\text { López- } \\
\text { Guzmán e } \\
\text { Sánchesz- } \\
\text { Canizares } \\
\text { (2012) e } \\
\text { Barber (2009) }\end{array}$ & Quantitativa/Survey & $\begin{array}{l}\text { Visitante da feira } \\
\text { MATKA2012 } \\
\text { - Helsinki } \\
\text { (Finlândia) }\end{array}$ \\
\hline $\begin{array}{c}\text { Schwart- } \\
\text { zhoffová } \\
\text { (2014) }\end{array}$ & $\begin{array}{c}\text { Eventos } \\
\text { e turismo } \\
\text { gastronômico }\end{array}$ & $\begin{array}{c}\text { As variáveis } \\
\text { podem ser } \\
\text { identificadas } \\
\text { nas análises dos } \\
\text { dados }\end{array}$ & - & Quantitativa/Survey & $\begin{array}{c}\text { Visitantes } \\
\text { de eventos } \\
\text { gastronômicos } \\
\text { da República } \\
\text { Tcheca }\end{array}$ \\
\hline $\begin{array}{c}\text { Sánchez et al. } \\
\text { (2014) }\end{array}$ & \begin{tabular}{|c|} 
Turismo \\
gastronômico, \\
pontos fortes, \\
pontos fracos, \\
oportunidades e \\
ameaças \\
\end{tabular} & $\begin{array}{l}\text { As variáveis } \\
\text { podem ser } \\
\text { identificadas na } \\
\text { metodologia }\end{array}$ & $\begin{array}{c}\text { Catálogo } \\
\text { Turístico da } \\
\text { Província de } \\
\text { Pastaza (2013) }\end{array}$ & Quantitativa/Survey & $\begin{array}{l}\text { Usuários } \\
\text { restaurantes } \\
\text { de Pastaza } \\
\text { (Equador) }\end{array}$ \\
\hline $\begin{array}{l}\text { Bizinelli et al. } \\
\text { (2015) }\end{array}$ & \begin{tabular}{|c|} 
Turismo e \\
alimentação e \\
distribuição dos \\
estabelecimentos
\end{tabular} & - & $\begin{array}{l}\text { Guia Quatro } \\
\text { Rodas (1989, } \\
2001 \text { e 2014) }\end{array}$ & $\begin{array}{c}\text { Qualitativa/análise } \\
\text { documental }\end{array}$ & $\begin{array}{c}\text { Restaurantes de } \\
\text { Curitiba/Paraná } \\
\text { (Brasil) }\end{array}$ \\
\hline $\begin{array}{l}\text { Londoño } \\
\text { (2015) }\end{array}$ & $\begin{array}{c}\text { Turismo } \\
\text { gastronômico e } \\
\text { stakeholders }\end{array}$ & - & $\begin{array}{c}\text { Hartley (1994), } \\
\text { Crewswell e } \\
\text { Miller (2000) }\end{array}$ & $\begin{array}{c}\text { Qualitativa/análise } \\
\text { documental }\end{array}$ & $\begin{array}{c}\text { Mercado de } \\
\text { gastronomia } \\
\text { da Catalúnia } \\
\text { (Espanha) }\end{array}$ \\
\hline $\begin{array}{l}\text { Teodoroiu } \\
\text { (2015) }\end{array}$ & $\begin{array}{c}\text { Alimentos típicos } \\
\text { da Romênia }\end{array}$ & - & - & $\begin{array}{l}\text { Qualitativa/ } \\
\text { Exploratório }\end{array}$ & $\begin{array}{c}\text { Alimentação } \\
\text { local da } \\
\text { Romênia }\end{array}$ \\
\hline $\begin{array}{l}\text { Ackovska, et } \\
\text { al. (2015) }\end{array}$ & $\begin{array}{l}\text { Agroturismo } \\
\text { e Turismo } \\
\text { gastronômico }\end{array}$ & - & - & Quantitativa/Survey & $\begin{array}{l}\text { República da } \\
\text { Macedônia }\end{array}$ \\
\hline $\begin{array}{l}\text { Bahls et al. } \\
\text { (2015) }\end{array}$ & $\begin{array}{l}\text { Planejamento } \\
\text { gastronômico }\end{array}$ & - & - & $\begin{array}{c}\text { Qualitativa/análise } \\
\text { documental }\end{array}$ & $\begin{array}{l}\text { Comparativo } \\
\text { entre Brasil } \\
\text { e o cenário } \\
\text { internacional }\end{array}$ \\
\hline $\begin{array}{l}\text { Kalenjuk et } \\
\text { al. (2015) }\end{array}$ & $\begin{array}{c}\text { Turismo } \\
\text { gastronômico }\end{array}$ & - & - & Quantitativa/Survey & $\begin{array}{l}\text { Catering - } \\
\text { Vojvodina/ } \\
\text { Sérvia }\end{array}$ \\
\hline $\begin{array}{l}\text { Meladze } \\
(2015)\end{array}$ & Alimentos típicos & - & - & $\begin{array}{c}\text { Qualitativa/Revisão } \\
\text { Teórica }\end{array}$ & $\begin{array}{l}\text { Restaurantes } \\
\text { Geórgia }\end{array}$ \\
\hline
\end{tabular}


Dor: 10.14210/rtva.v20n4.p184-208

\begin{tabular}{|c|c|c|c|c|c|}
\hline Pesquisa & Variáveis & Instrumento & $\begin{array}{l}\text { Referências de } \\
\text { Apoio }\end{array}$ & Método & Objeto \\
\hline $\begin{array}{c}\text { Morales- } \\
\text { Fernández et } \\
\text { al. (2015) }\end{array}$ & $\begin{array}{c}\text { Turismo rural, } \\
\text { denominação } \\
\text { de origem (óleo } \\
\text { turistas) }\end{array}$ & $\begin{array}{c}\text { As variáveis } \\
\text { podem ser } \\
\text { identificadas } \\
\text { nas análises dos } \\
\text { dados }\end{array}$ & - & Quantitativa/Survey & $\begin{array}{c}\text { Óleo turista } \\
\text { de Córdoba } \\
\text { (Espanha) }\end{array}$ \\
\hline $\begin{array}{l}\text { Torre \& Rojas } \\
\quad(2015)\end{array}$ & $\begin{array}{c}\text { Turismo } \\
\text { gastronômico }\end{array}$ & $\begin{array}{l}\text { As variáveis } \\
\text { podem ser } \\
\text { identificadas } \\
\text { na metodologia } \\
\text { e análises dos } \\
\text { dados }\end{array}$ & - & Quantitativa/Survey & $\begin{array}{c}\text { Empresários do } \\
\text { setor hoteleiro } \\
\text { de Córdoba } \\
\text { (Espanha) }\end{array}$ \\
\hline Forné (2016) & $\begin{array}{c}\text { Turismo } \\
\text { gastronômico e } \\
\text { desenvolvimento } \\
\text { local }\end{array}$ & - & $\begin{array}{l}\text { Patronato de } \\
\text { la Vall de Boí } \\
(2014)\end{array}$ & $\begin{array}{l}\text { Qualitativa/análise } \\
\text { documental }\end{array}$ & $\begin{array}{l}\text { Queijo como } \\
\text { produto típico } \\
\text { de Vall de Boí } \\
\text { (Espanha) }\end{array}$ \\
\hline $\begin{array}{l}\text { Jemabey } \\
(2016)\end{array}$ & $\begin{array}{c}\text { Rotas } \\
\text { gastronômicas e } \\
\text { desenvolvimento } \\
\text { local }\end{array}$ & $\begin{array}{c}\text { O questionário } \\
\text { semiestruturado } \\
\text { encontra-se na } \\
\text { metodologia da } \\
\text { pesquisa }\end{array}$ & - & $\begin{array}{l}\text { Qualitativa/análise de } \\
\text { conteúdo }\end{array}$ & $\begin{array}{c}\text { Rotas } \\
\text { gastronômicas } \\
\text { da Catalunha } \\
\text { (Espanha) }\end{array}$ \\
\hline $\begin{array}{l}\text { Martins et al. } \\
\quad(2016)\end{array}$ & $\begin{array}{l}\text { Turismo } \\
\text { gastronômico e } \\
\text { slow food }\end{array}$ & - & - & Qualitativa/Descritiva & $\begin{array}{c}\text { Experiências } \\
\text { gastronômicas } \\
\text { em Recife/ } \\
\text { Pernambuco } \\
\text { (Brasil) }\end{array}$ \\
\hline $\begin{array}{l}\text { Gordin et al. } \\
\quad(2016)\end{array}$ & $\begin{array}{l}\text { Papel dos } \\
\text { restaurantes } \\
\text { como promotor da } \\
\text { gastronomia local }\end{array}$ & - & $\begin{array}{l}\text { Gordin and } \\
\text { Trabskaya } \\
\text { (2013) }\end{array}$ & Quantitativa/Survey & $\begin{array}{c}\text { Restaurantes } \\
\text { da Finlândia, } \\
\text { Espanha, } \\
\text { Alemanha, Itália, } \\
\text { Rússia e França }\end{array}$ \\
\hline
\end{tabular}

Fonte: Elaboração própria.

\section{CONTRIBUIÇÃO DOS AUTORES NA CONSTRUÇÃO DO ARTIGO}

Ribeiro-Martins: Definição do objetivo de pesquisa, Fundamentação teórica, Definição dos procedimentos metodológicos, Análise dos dados, Interpretação dos resultados, Revisão crítica da pesquisa, Redação da pesquisa.

Silveira-Martins:Definiçãodoobjetivodepesquisa, Definiçãodos procedimentos metodológicos, Coleta de dados, Análise dos dados, Interpretação dos resultados, Revisão de normas e ortografia, Redação da pesquisa. 